JOURNAL DE PHYSIQUE IV

Colloque C4, supplément au Journal de Physique III, Vol. 1, novembre 1991

\title{
INTERNAL STRESS EFFECT IN THE SHAPE MEMORY BEHAVIOUR
}

\author{
E. PATOOR, P. BARBE, A. EBERHARDT and M. BERVEILLER \\ Institut Supérieur de Génie Mécanique et Productique, Université de Metz, Ile du Saulcy, F-57045 \\ Metz cedex, France
}

\begin{abstract}
Internal stress associated with an oriented microstructure of defects are taken into ac count in the thermoelastic balance of martensitic phase transition. From this analysis a macros copic flow rule is determined for the TWME by using a phenomenological approach based on a yield criterion derived from Gibb's free energy expression. Experiments perfor med on a $\mathrm{Cu}-\mathrm{Zn}-\mathrm{Al}$ polycrystalline alloy trained with a cyclic uniaxial tension test are used for identifying the modelling parameters.
\end{abstract}

\section{Introduction.}

Two Way Memory Effect (TWME) is a resultat of a large number of training sequences. It has been shown that these training sequences produce oriented defects into the material (dislocations, precipitates, residual phase...) which are responsible for the existance of an internal stress field [1].

In this paper the TWME is described by taking into account the effect of such internal stress in the thermoelastic balance of the transformation. We assume that the chemical driving force is not affected by the training process, the existence of defects is only considered from a mechanical point of view. Phenomena like change in the degree of the order of the martensitic phase are not taken into account by this ap proach. In this way we establish that such internal stress field act exactly as an applied stress on the energy balance of the transformation. This result allows us to represent the effects of education by introducing a kinematical hardening variable in a macroscopic transformation criterion. A phenomenological flow rule associated with this criterion is then determined for the TWME. This result is consistent with numerous observations made by different authors on the consequences of education on the overall behaviour of the material, such as shifts in the phase transition temperature, decrease in the critical stress necessary to stress-induced the transformation and the low value of the education efficiency.

\section{Experimental observations.}

Most of training experiments reported in the litterature are performed with non uniform stress field loading (torsion, flexion). In order to identify the modelling parameters it is necessary to characterize the overall behaviour with a homogeneous stress field through out the specimen.

A commercial $\mathrm{Cu}-\mathrm{Zn}$-Al produced by TREFIMETAUX Company was used in this study. The nominal composition of the material was $\mathrm{Cu}-27.3 \% \mathrm{Zn}-3.7 \% \mathrm{Al}$ in weight. The samples were plates of $2 \times 8 \times$ $100 \mathrm{~mm}^{3}$. Specimens were betatized for $180 \mathrm{~s}$ at $850^{\circ} \mathrm{C}$, water-quenched and maintained $3.6 \mathrm{Ks}$ at $100^{\circ} \mathrm{C}$. A grain size of $1 \mathrm{~mm}$ was obtained. The transformation temperature was $\mathrm{M}_{\mathrm{S}}=-4^{\circ} \mathrm{C}$. The Supe relastic training sequences were performed on a tensile machine with maximum strain imposed (fig. 1 ).

The irreversible strain, $\mathrm{E}^{\mathrm{P}}$ accumulated after each loading-unloading sequences is graphed against the number of cycles (fig. 2 ).

After an intial rapid increase in the plastic strain, the rate of change tends to level off. When the $\mathrm{E}^{\mathrm{P}}$ is stabilized, the retained martensite was reverted to austenite by flash heating at $150^{\circ} \mathrm{C}$. Strain $\mathrm{E}^{\mathrm{P}}$ was then partly recovered and a two way memory of $0.79 \%$ was obtained (fig. 3 ). The efficiency of this training is then equal to $40 \%$. 


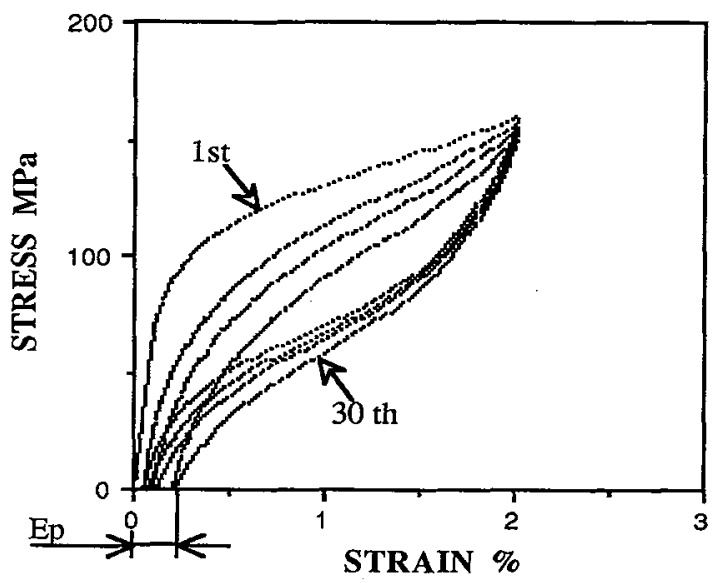

Figure 1: Superelastic training with a constant maximal strain $\left(\varepsilon^{\max }=2 \%\right)$ at constant temperature $\left(\mathrm{T}=20^{\circ} \mathrm{C}\right)$ for a polycrystalline $\mathrm{Cu}-\mathrm{Zn}-\mathrm{Al}$ alloy : evolution of the stress-strain curves with the cycle number.

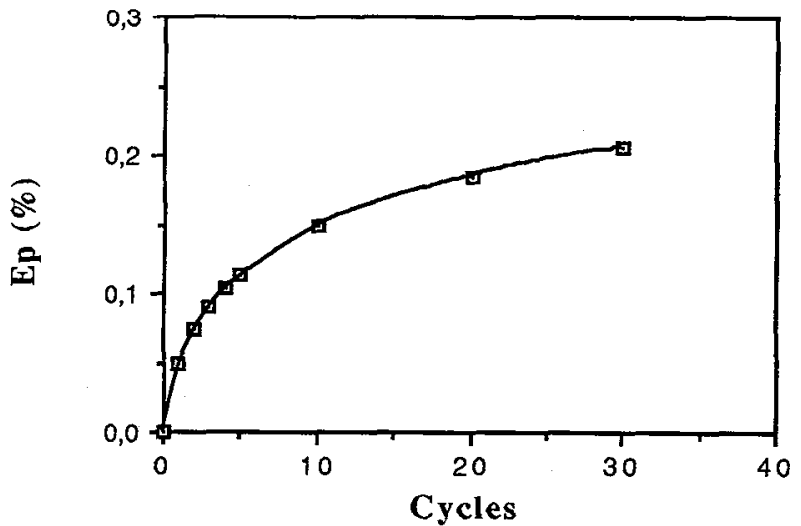

Figure 2. Evolution of the residual macroscopic plastic strain $\mathrm{E}^{\mathrm{P}}$ with the cycle number for superelastic training represented in fig. $1 .\left(\mathrm{T}=20^{\circ} \mathrm{C}, \varepsilon^{\max }=2 \%\right)$.

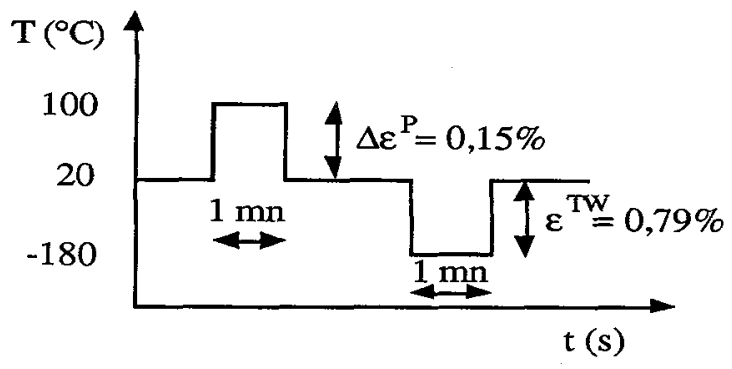

Figure 3. Behaviour of a polycrystalline $\mathrm{Cu}-\mathrm{Zn}-\mathrm{Al}$ alloys after 30 cycles of superelastic training at constant maximal strain and temperature $\left(\mathrm{T}=20^{\circ} \mathrm{C}, \varepsilon^{\max }=2 \%\right)$. 
3.Strain analysis in phase transition.

The total strain field $\varepsilon^{\mathrm{T}}(\mathrm{r})$ obtained during a martensitic transformation is composed of inelastic and elastic parts. Microstructural observations [2] [3] [4] have shown that the fundamental mechanism of all the training methods is the introduction of some oriented defects into the material (dislocations, precipitates, residual phase...). These defects can move over a certain distance producing a few irreversible plastic strain $\varepsilon^{P}$. Thus the inelastic contributions are the transformation strain $\varepsilon^{M}(r)$ and the plastic strain $\varepsilon^{P}(r)$. The total strain field resulting from the superposition of inelastic strains $\varepsilon^{\mathrm{M}}$ and $\varepsilon^{\mathrm{P}}$ and elastic one $\varepsilon^{\mathrm{O}}$ due to an external loading $\sigma^{\circ}$ generally does not satisfy the compatibility conditions. It is necessary to in troduced a supplementary elastic strain field $\varepsilon^{\mathrm{e}}(\mathrm{r})$ in order to assume the compatibility of the total strain field $\varepsilon^{\mathrm{T}}$, now expressed by

$$
\varepsilon^{\mathrm{T}}(\mathrm{r})=\varepsilon^{\mathrm{M}}(\mathbf{r})+\varepsilon^{\mathrm{o}}(\mathbf{r})+\varepsilon^{\mathrm{P}}(\mathrm{r})+\varepsilon^{\mathrm{e}}(\mathbf{r})
$$

The macroscopic deformation $\mathrm{E}^{\mathrm{T}}$ observed during phase transition, is given by the mean volumic value of this field

$$
\mathrm{E}^{\mathrm{T}}=\frac{1}{\mathrm{~V}} \int_{\mathrm{V}} \varepsilon^{\mathrm{T}}(\mathrm{r}) \mathrm{dV}
$$

After unloading by a fully reverse transformation, $\varepsilon^{\circ}$ and $\varepsilon^{M}$ return to zero, but the inelastic strain field $\varepsilon^{\mathrm{P}}(\mathrm{r})$ associated with the defects does not disappear. To assume the compatibility of this residual strain an elastic strain field $\varepsilon^{\mathrm{eP}}(\mathrm{r})$ (which is generally different than the previous one $\varepsilon^{\mathrm{e}}(\mathrm{r})$ ) does exist. The total compatible residual strain field is then described by

$$
\varepsilon^{R e s}(r)=\varepsilon^{P}(r)+\varepsilon^{e P}(r)
$$

If the elasticity is homogeneous, the mean value of this residual strain field gives only a plastic deformation $\mathrm{E}^{\mathrm{P}}$ defined by:

$$
E^{P}=\frac{1}{V} \int_{V} \varepsilon^{P}(r) d V
$$

This deformation which evolves during the training sequence is observed upon the unloading of the superlastic specimen (fig. 1 ). Successive transformations increase the irreversible plastic strain $E^{P}$ [5][11](fig.2.). Thus $\mathrm{E}^{\mathrm{P}}$, generated by accumulation and movement of defects during the training, is an indirect indicator of the internal state of the material.

Despite the fact that $\varepsilon^{\mathrm{eP}}(\mathrm{r})$ does not contribute to the macroscopic strain, this term has a great influence on the behaviour of the material because it is linked, through the Hooke's law, to an internal stress field $\sigma^{\mathrm{s}}$.

\section{Thermoelastic balance in presence of defects.}

The variation of the non chemical free energy is composed by the difference of the mechanical energy between the transformed and untransformed states. This quantity is generaly divided among $\mathrm{E}_{\text {int }}$, the interaction energy with the applied stress $\sigma^{\circ}$ and $E_{\mathrm{el}}$, the elastic energy associated with the incompatibili ties of the inelastic strain field $\varepsilon^{\mathrm{M}}$ describing the phase transformation. To take into account the role of internal stresses generated by the training process, a recalculation of the variation of mechanical energy is necessary. This is performed with the assumption that the chemical driving force is unafected.

If we consider a volume $V$ of austenic phase, limited by a boundary $S$, its potential energy $W^{\circ}$ due to the superposition of surface forces $F$, applied stress $\sigma^{\mathrm{o}}$ and internal stresses $\sigma^{\mathrm{s}}$, is expressed by

$$
W^{o}=\frac{1}{2} \int_{V}\left(\sigma_{i j}^{o}+\sigma_{i j}^{s}\right)\left(\varepsilon_{i j}^{o}+\varepsilon_{i j}^{e P}\right) d V-\int_{S} F_{i}\left(u_{i}^{o}+u_{i}^{P}\right) d S
$$

In the martensitic state, the potential energy is modified. The internal stress $\sigma^{\text {inc }}$, related by Hooke's law to the elastic strain $\varepsilon^{\mathbf{e}}$, is differs from $\sigma^{\mathbf{s}}$ defined in the untransformed state. In order to determine the change in the potential energy due to the phase transformation, we consider that $\varepsilon^{e}$ is composed of two elastic contributions with different physical meanings. 


$$
\varepsilon^{\mathrm{e}}(\mathrm{r})=\varepsilon^{\mathrm{eP}}(\mathrm{r})+\varepsilon^{\mathrm{eM}}(\mathrm{r})
$$

where $\varepsilon^{\mathrm{eP}}$ is the elastic strain previously associated to $\sigma^{\mathrm{S}}$ and $\varepsilon^{\mathrm{eM}}$ is an elastic strain field due to the in compatibilities of the transformation strain $\varepsilon^{\mathrm{M}}$. The internal stress associated to $\varepsilon^{\mathrm{e}}(r)$ is then composed of two contributions, $\sigma^{\mathrm{S}}$, associated with the defects and $\sigma^{\mathrm{M}}$, the internal stress field related to the elastic strain $\varepsilon^{\mathrm{eM}}$ by Hooke's law.

The potential energy after phase transformation, denoted by $\mathrm{W}^{1}$, is then expressed by

$$
\begin{aligned}
W^{1}=\frac{1}{2} \int_{V}\left(\sigma_{i j}^{o}\right. & \left.+\sigma_{i j}^{S}+\sigma_{i j}^{M}\right)\left(\varepsilon_{i j}^{o}+\varepsilon_{i j}^{e P}+\varepsilon_{i j}^{e M}\right) d V \\
& -\int_{S} F_{i}\left(u_{i}^{o}+u_{i}^{P}+u_{i}^{M}\right) d S
\end{aligned}
$$

From relations (5) and (7) the change in potential energy associated with a martensitic transformation in a trained sample is expressed by:

$$
\begin{aligned}
\Delta W=W^{1}-W^{0}=\frac{1}{2} \int_{V} \sigma_{i j}^{M}\left(\varepsilon_{i j}^{o}+\varepsilon_{i j}^{e P}+\varepsilon_{i j}^{e M}\right) d V+\frac{1}{2} \int_{V}\left(\sigma_{i j}^{o}+\sigma_{i j}^{S}\right) \varepsilon_{i j}^{e M} d V \\
-\int_{S} F_{i} u_{i}^{M} d S
\end{aligned}
$$

After calculation the variation of mechanical energy associated with a martensitic transformation in presence of defects, is finally expressed by [6]:

$$
\Delta W=-\int_{V}\left(\sigma_{i j}^{o}+\sigma_{i j}^{S}\right) \varepsilon_{i j}^{M} d V-\frac{1}{2} \int_{V} \sigma_{i j}^{M} \varepsilon_{i j}^{M} d V
$$

This relation is very closed to the one previously given for a free-defect material [7]. The internal stress field $\sigma^{S}$ introduced into the material by the training process, acts as a supplementary loading stress. In a trained material, the variation of Gibb's Free energy due to a thermoelastic martensitic transformation is expressed by:

$$
\Delta G=\Delta G_{c h}-\int_{V}\left(\sigma_{i j}^{o}+\sigma_{i j}^{S}\right) \varepsilon_{i j}^{M} d V-\frac{1}{2} \int_{V} \sigma_{i j}^{M} \varepsilon_{i j}^{M} d V
$$

In this relation $\Delta \mathrm{G}_{\mathrm{ch}}$ is considered as the chemical free-energy of an ideal free-defect material. At a given temperature $T$ and for an initial volume $V$ of austenite, this variation is constituted by the difference between the chemical free energy for a transformed volume $V_{M}$ and for volume $\left(V-V_{M}\right)$ of the parent phase. This quantity is generaly related to the temperature by the usual linear relation

$$
\Delta \mathrm{G}_{\mathrm{ch}}=\mathrm{B}\left(\mathrm{T}-\mathrm{M}_{\mathrm{S}}\right) \mathrm{V}_{\mathrm{M}}
$$

where $M_{S}$, the Martensitic Start temperature, is the temperature where the transformation occurs in a free stress state and $\mathrm{B}$ is a coefficient which is related to the chemical composition and to the nature of the transformation. For practical uses, the measurement of the $\mathrm{M}_{\mathrm{S}}$ temperature before the training sequence, give a good approximation of this quantity.

\section{Transformation criterion and associated flow rule for TWME.}

From this result a new criterion of transformation, taking into account the presence of defects, is determined. At the beginning of the transformation the internal stress field $\sigma^{\mathrm{M}}$ associated to the $\varepsilon^{\mathrm{M}}$ field, equals zero. Thus the transformation takes place when the following relation is verified :

$$
\int_{V}\left(\sigma_{i j}^{o}+\sigma_{i j}^{S}\right) \varepsilon_{i j}^{M} d V=B\left(T-M_{S}\right) V_{M}
$$

This relation shows that the applied stress necessary to induce the transformation is modified by the pre- 
sence of defects. It is reasonnable to assume that both residual plastic strain $\varepsilon^{P}$ and internal stress $\sigma^{S}$ were oriented by the training stress. Thus when $\sigma^{\circ}$ and the training stress have the same orientation, $\sigma^{S}$ has the same orientation as $\sigma^{\circ}$. In such a case the critical stress necessary to produce the transformation decreases. This was experimentally observed in samples submitted to superelastic training [5],[8] (fig.1). Relation (12) can be expressed as a macroscopic transformation criterion, with the assumptions that there are no volume changes and that the behaviour is isotropic, a Von Mises criterion can be substituted for condition (12). In that case, the microstructural effect of training is taken into account by the introduction of a kinematical hardening variable $\mathrm{x}_{\mathrm{ij}}[9]$ :

$$
\frac{1}{2}\left(s_{i j}^{o}+x_{i j}\right)\left(s_{i j}^{o}+x_{i j}\right)=K^{2}(T)
$$

where $s^{\circ}$ denotes the deviatoric part of the applied stress tensor $\sigma^{\circ}$ and $\mathrm{x}$ characterizes the internal stress induced by the training. The training variable, $x$, is dependent upon the type of training and it is a function of the number of cycles performed. The temperature related function $K(T)$ is identified on a virgin material $\left(\mathrm{x}_{\mathrm{ij}}=0\right)$, overall criterion (13) becomes [7]:

$$
F\left(\sigma^{o}, T, x\right)=\frac{1}{2}\left(s_{i j}^{o}+x_{i j}\right)\left(s_{i j}^{o}+x_{i j}\right)-\left[\frac{B}{g}\left(T-M_{s}\right)\right]^{2}=0
$$

where $g$ denotes the transformation shear strain which is determined by using the WLR theory [10].

In the case of standard material, the phenomenological flow rule associated to a macroscopic yield function $F\left(\sigma^{\circ}, T, x\right)$ is defined by

$$
d E_{i j}^{T P}=a\left(E^{T P}, E^{P}\right) \frac{\partial F\left(\sigma^{\circ}, T, x\right)}{\partial \sigma_{i j}^{o}}\left[\frac{\partial F\left(\sigma^{o}, T, x\right)}{\partial \sigma_{h k}^{o}} d \sigma_{h k}^{o}-\frac{\partial F\left(\sigma^{o}, T, x\right)}{\partial T} d T\right]
$$

According to (14) the thermomechanical behaviour of a trained shape memory alloy is described in a phenomenological way by the following relation

$$
\mathrm{dE}_{\mathrm{ij}}^{\mathrm{TP}}=\mathrm{a}\left(\mathrm{E}^{\mathrm{TP}}, \mathrm{E}^{\mathrm{P}}\right)\left(\mathrm{s}_{\mathrm{ij}}^{\mathrm{o}}+\mathrm{x}_{\mathrm{ij}}\right)\left[\left(\mathrm{s}_{\mathrm{hk}}^{\mathrm{o}}+\mathrm{x}_{\mathrm{hk}}\right) \mathrm{d} \sigma_{\mathrm{hk}}^{\circ}-2\left(\frac{\mathrm{B}}{\mathrm{g}}\right)^{2}\left(\mathrm{~T}-\mathrm{M}_{\mathrm{S}}\right) \mathrm{dT}\right]
$$

Relation (16) has the advantage of yielding a very simple and analytical description of the overall beha viour of shape memory trained samples. In this relation the temperature $\mathrm{M}_{\mathrm{S}}$ is a characteristic of the material which may be measured before the training sequence. In the phenomenological approach developed here, the influence of the variation of the microstructural state on the overall behaviour, is taken into account with a function a $\left(E^{T P}, E^{P}\right)$. This function must be experimentally determined by a particular loa ding (for exemple tension test). In order to take into account the evolution of the internal state during the training, this determination must be performed for each cycle of transformation. The influence of training sequences on the microstructure is characterized by the overall parameter $\mathrm{E}^{\mathrm{P}}(8)$. In consequence the knowledge of a macroscopic yield criterion for the thermoelastic martensitic transformation and the identification of the function a $\left(\mathrm{E}^{\mathrm{TP}}, \mathrm{E}^{\mathrm{P}}\right)$ for one particular loading at different training levels yields in formation about the overall behaviour of the material during a stress-induced transformation (due to applied or internal stresses ). The experimentally determined function $a\left(\mathrm{E}^{\mathrm{TP}}, \mathrm{E}^{\mathrm{P}}\right)$ is an easier way to take into account the effect of the complex evolutions of the microstructure during the transformation and during training cycling on the overall behaviour.

\section{Discussion.}

The major features of TWME is its ability to yield samples which, after training and without applied stress change shape spontaneously when cooling and also significantly increase the transition temperature of the material. The introduction of a kinematical hardening variable, which represents the effects of the internal stress field associated to the existence of an oriented microstructure of defects, allows for an accurate description of these phenomena.Flow rule (16), describes the overall deformation $\mathrm{E}^{\mathrm{PT}}$ observed on cooling trained samples without applied stress : 


$$
\mathrm{dE}^{\mathrm{PT}}=-2 \mathrm{a}\left(\mathrm{E}^{\mathrm{P}}, \mathrm{E}^{\mathrm{PT}}\right) \mathrm{x}_{\mathrm{ij}}\left(\frac{\mathrm{B}}{\mathrm{g}}\right)^{2}\left(\mathrm{~T}-\mathrm{M}_{\mathrm{S}}\right) \mathrm{dT}
$$

This deformation is oriented by the training sequence through $x_{i j}$, this is in agreement with the observa tions that samples trained in tension (resp. in torsion) deforms spontaneously in the same way during cooling(fig. 3.) [5]. A modified temperature of transformation $\mathrm{T}_{\mathrm{S}}$ can be defined by setting $\mathrm{s}_{\mathrm{ij}}{ }^{\circ}$ equal to zero in criterion (14).

$$
T_{S}=M_{S}+\frac{g}{B} \sqrt{\frac{1}{2} x_{i j} x_{i j}}
$$

This temperature is greater than the $\mathrm{M}_{\mathrm{S}}$ temperature of the initial material. Experimental works take in evidence that if the $M_{S}$ temperature is affected by the training, the temperature of end of transformation $\left(\mathrm{M}_{\mathrm{f}}\right)$ remains quite constant [5], [11]. This observation can be explained in a qualitative way by the proposed model. At the begining of the transformation internal stress $\sigma^{\mathrm{s}}$ associated with defects are able to strongly affect the phase transformation temperature (see (18)). During the tranformation process the growing of martensite plates which were oriented by $\sigma^{S}$ tend to accommodate the incompatibilities due to the defects. It is then reasonnable to assume that at the end of the transformation such defects are tota ly accommodated and the $\mathbf{M}_{\mathrm{f}}$ temperature is unaffected .

This explanation is in agreement with metallographical observations performed on educated coil-spring actuators [12]. It is observed that cooling without applied stress produces a stress-induced microstructure in the begining and self-accommodated plates at the end of the transformation. Simultaneous measurements of the volumic fraction of martensite (by resistivity) and the elongation obtained during the heating show that $70 \%$ of the displacement is produced by only $30 \%$ of the transformed volume. Similar observations are made by [5], [13]. This mecanism explains why the education efficiency ratio is generaly less than $60 \%$. Even if a large part of the material is affected by the training, only a fraction of this volume could be transformed in an oriented way and then contributed to the macroscopic shape change.

TWME is a particular behaviour of the Shape Memory Alloys where the internal state of the material plays the major role. A complete description of this thermomechanical behaviour implies that one is to take into account the evolution of the different sources of incompatibilities (defects and phase transition) during the transformation. The phenomenological flow rule and criterion which were outlined in this paper nevertheless give us a good description of this typical behaviour.

ACKNOWLEDGEMENT : extended discussions on the TWME with Pr. Gerard GUENIN are gratefully acknowledged.

\section{REFERENCES,}

1/ WAYMAN C. M. and DUERIG T. W., in Engineering Aspects of Shape Memory Alloys, Ed. by DUERIG T. W., (1990) 3.

12/ PERKINS J. and BOBOWIEC P., Metall. Trans., 17A (1986) 195.

B/. RIOS JARA D. and GUENIN G., Acta Metall., 35 (1987) 109 and 121.

14/ PERKINS J and SPONHOLZ R. O., Metal. Trans. A, 15A (1984) 313.

15/ CONTARDO L. and GUENIN G., Acta metall. mater, 38 (1990) 1267.

16/ PATOOR E., EBERHARDT A. and BERVEILLER M., to be published.

17/ PATOOR E., EBERHARDT A. and BERVEILLER M., Acta Metall., 35 (1987) 2779.

/8/ EUCKEN S. and DUERIG T.W., Acta Metall., 37 (1989) 2245

19/ PATOOR E., EBERHARDT A. and BERVELLER M., Rev. Traitement Thermique, 234 (1990) 43.

/10/ WECHSLER M.S., LIEBERMAN D.S. and READ, T.A., Trans. AIME, 197 (1953) 1503.

/11/ LI J. C. and ANSEL G. S., Metal. Trans., 14A (1983) 1293.

/121/ FRIEND C. M., Scripta Met., 20 (1986) 995.

/13/ MELTON K. N. and MERCIER O., Scripta Met., 12 (1978) 5. 